\title{
Total Quality Management \& Service Sector
}

\author{
Afnan Atiah Alsolamy ${ }^{1}$ Khulood Salem Albeladi ${ }^{2}$ Syed Hamid Hasan ${ }^{3}$ \\ ${ }^{1,2,3}$ Faculty of Computing and Information Technology, Department of Information Systems \\ King Abdulaziz University, Kingdom of Saudi Arabia \\ shh786@hotmail.com
}

\begin{abstract}
The following paper highlights the domination of quality service and adaptation of Total Quality Management in the service Industry. It tries to explain that along with the increasing awareness in the society in respect to culture, education and the living standard, there is an increasing demand for quality service. It is one of the factors that is forcing the service industry to adopt TQM (total quality management) as the measures to improving quality of service.

It has been observed that TQM is being accepted increasingly in the last decade by the service sector which clearly signifies that service quality is treated as a crucial factor for survival, Success \& growth by the companies. This has led to an increased interest in service quality recently, and TQM concepts increasingly being applied in literature for service sector
\end{abstract}

Keywords: TQM (Total Quality Management), Service Quality, Continual Improvement

\section{Council for Innovative Research}

Peer Review Research Publishing System

Journal: International Journal of Management \& Information Technology

Vol. 6, No. 3

editor@cirworld.com

www.cirworld.com, member.cirworld.com 


\section{INTRODUCTION}

\section{TQM- Total Quality Management}

The term TQM can be broken into its components where Total means all Activities and each individual is governed by Quality in a company. Quality means compliance with the requirements of the customer. Management means that management of Quality is possible and must be done. Thus TQM means that it is a process of managing quality in such a way that it conforms to customer requirements and covers all aspects in the company; it is a process of continual improvement or can even be termed as a way of living or a philosophy. TQM was the hot topic in the 80's however it has had its ups and downs. The concepts and principle of TQM even though simple have gained importance in parts through development of "Management Quality System" standards: ISO9001.

Even though TQM is being applied widely practiced, very few agree on its meaning [1]. It was first introduced by Feigenbaumin the year 1961, and he called it TQC (total quality control). Starting from the 1950s, people like Juran, Deming \& Crosby, taught about quality ideas for over 40 years, but they did not use the word 'total'. However when the European Foundation of Quality Management was created in 1988, TQM was stressed upon as the means to achieve "total customer satisfaction'. TQM was defined as “Total Quality Control's organization wide impact” by Feigenbaum, who was the inventor of the term.

\section{Service-Quality}

Defining of quality is difficult and it is a known issue for the service industry, thus making it increasingly difficult to arrive at a consensus on the definition of quality with respect to the service sector and developing the term "Service Quality". The factors that separate goods from services are that services are perishable, heterogeneous, inseparable with respect to production \& consumption, and intangible. The issue is further accuted by the essential dependence on perception of customers, as the subjective \& intangible element are with the introduced. Hence, it is challenging to measure the Service Quality. To define "service quality", to define Beauty as both of them are completely based on perception and means different to different people.

\section{TQM - PRINCIPALS}

TQM has the following major principles:

\section{Commitment from Management}

- $\quad$ To Plan (direct \& drive)

- $\quad$ To Do (execute, participate \& support)

- To Check (evaluate)

- To Act (identify, communicate, adapt)

Empower Employees

- Train

- $\quad$ Suggest

- Measure, Recognize \& Reward

- Excellence teams

\section{Decision Making based on Facts}

- $\quad$ Statistical process-control (SPC)

- $\quad$ Failure mode and effects analysis(FMEA) \& DOE : Design of Experiments

- The 7 statistical tool

- $\quad$ Team Oriented Problem-Solving - TOPS - (FORD 8D)

\section{Continual Improvement}

- Focus on CONQ and Systematic measurements

- Excellence team

- Process-management across functions

- Accomplish, preserve, improve standards

\section{Focus on Customers}

- Partnership with Supplier

- Service relationships of internal customers

- No compromise on quality

- Standards driven by Customer

\section{SERVICE INDUSTRY AND TQM}

During the initial phase of Total Quality Management, the entire effort was to adapt and develop the concept of TQM for application to the Production industry only. Quality parameters were not really defined for the Service Industry. However, it was not before the need of TQM began growing in the service sector owing to the increasing competition and the demand of quality service. The most significant question at that times was whether the principles of TQM can be applied to Service Sector. Various researchers presented studies and view-points that resulted in the latest developments in the concept of TQM and made it suitable for the application to Service Sector. 
The late 80 s and early 90 s saw bigger approval and application of the concept in service Industry [2], by service quality being treated as a crucial factor for survival, Success \& growth by the companies [3]. It has been observed that TQM is being accepted increasingly in the last decade by the service sector [4]. It is difficult to define quality [5], it is a known issue for the service industry [6], because of the factors that separate goods from services. i.e.services are perishable, heterogeneous, inseparable with respect to production \& consumption, and intangible [7] The issue is further accuted by the essential dependence on perception of customers, as the subjective \& intangible element are with the introduced. These difference have made it difficult to standardize quality, caused variations in service quality between different situations in the same organizations [8]. The specific characteristic of service, namely that they are subjective and intangible for most of the services, makes it more difficult to quantify of quality [9]. So, the task to measure service quality is posed itself as a challenge [10]. To define "service quality", is similar to define beauty as both of them are completely based on perception and means different to different people. Berry et al., (1990), considers the consumer to be the only judge for service quality because, service quality is the resultant of the comparison between the Expectation of the customer before they received service and the actual experience during the service by the customers. Service quality, mean the comparison done by the customers between their Expectation $(E)$ of the service before they receive it and the Perception $(P)$ of the service after they receive it. [11] Even though many of the researchers go with the PerceptionExpectation = Service Quality theory, yet quite a few issues have been highlighted. [12] Still the relationship between $E$ \& $P$ is disputed, no matter how casual it is [13], and it is possible that the customers might have different perception of quality. Nonetheless, the definition of Quality revolves around the customer $(\mathrm{N})$, with the satisfaction of the customers termed as function of quality which the customer perceives [14], or the other way round where customers' perception of quality is functions of his satisfaction [15]. Berry \& Parasuraman, Zetham[16], suggested that service quality has 10 dimensions of that are : understanding customers, courtesy, reliability, security, access, responsiveness, credibility, competence \& tangibles. Which were eventually cut down to responsiveness, tangible, empathy, assurance \& reliability. Sasser et al., (1978 b), recognized them to be training , availability, condition, completeness, attitude, consistency, and Security. Gronroos (1990), termed them to be flexibility \& recovery, credibility \& reputation, behavior \& attitudes, skill \& professionalism, accessibility, trustworthiness and reliability. While Schvaneveldt et aL, (1991), believed they are performance \& completeness, environment, emotion, ease of use, responsiveness and accuracy. ASLOG ('American Society for Logistics) (ASLOG), suggest we can define service quality through after-sale services, reliability, flexibility, organization, time and communications.

Service quality, does not have any distinct guideline or methodology to measure Quality [17], even though we have a number of terminologies \& methodologies being proposed. Parasuraman Ct al., (1988, 1991, 1993, and 1994) developed SERVQUAL a measuring tool for service quality which is the most widely accepted and tested. It has its basis on the 'gap model' of service quality. It define service quality as a function of P minus E. Schvaneveldt et al., (1991), suggested another method to measure service quality bases on two factors first, being the objective factor which would depend on the absence or presence of a specific dimension of quality next being the subjective factor deals with the resultant dissatisfaction or satisfaction of the user from the service. Cronin and Taylor disputed the aptness of $P$ minus $E$ approach so they came up with another instrument called SERVPERF, which measures performance only, and is has its basis on the principle that "We cannot measure Service quality treating it as an attitude or for that matter the perception of the customers". Teas, developed the NQ Model (Normal-Quality model), which treats expectations in two different modes - in the idea mode, where each attribute is given the highest-possible score, and the feasible mode where consideration to the actual circumstances in which the service is delivered is given in turn, stimulating possible distinctive effect.

\section{DIFFERENCE IN SERVICE INDUSTRY}

The Quality Control methods were designed and developed in the manufacturing sector. Which deal with fabrication and processing of material into finished goods. However, service is a different ball game all together and does not involve any noticeable manufacturing. The task is performed for somebody else. Additionally, the main difference between manufacturing and service sector is that the resultant product is: employees don't treat it as a product; directly delivered to the customer, most of the times; perishable; short-lived and intangible. Since the service directly delivered to the customer it brings the factors of unpredictability and uncertainty into the process. As it's usually hard to ascertain what the customer exactly wants and what according to him standard service is. The issue is aggravated by the factor that standard are usually judgmental, based on mood or personal preferences instead of specific performance metric which is measureable (King, 1985).

It means that it is not necessary that if a specific service has satisfied the customer on a specific day, then it will always satisfy him always, because the customer may be in a different mood on a different day. So satisfaction is dependent on the mood of the customer.

Additionally, as the products offered as service are perishable, so we cannot stock them ready for delivery, on the other hand they should be produced only when required. Thus there are many components involved in the delivery of the service, making it a complex process which requires perfect coordination by all parties involved, do deliver the product in time to the customer. While in case of manufacturing industry, even though timely delivery is required but it does not have any bearing on the quality of the product. For service industry, time is one of the components on which the quality if the service is measured and determined. Like aviation industry revolves around timely arrival and departure of the flights which is considered as factor of determining quality of an airline. Inflight entertainment and comfort are also considered by the customer for booking flights, however, no matter how comfortable the flight is, if it does not reach in time it is unlikely that customer would rate it good on quality. 
Intangibility of a product not only means that it cannot be physically seen or touched, but it is difficult to quantify the factors that are part of the quality of the product, and this feature of the service products make it difficult for TQM to measure the quality of products in the service industry.

\section{TQM - HOW TO IMPLEMENT IN SERVICE INDUSTRY}

To implement TQM in the service industry we can use the following steps:

1. Define the Strategy for service quality.

2. Study the process and define measures of quality for those processes

3. Establish the system for process control

4. Identify the opportunities of improvement by investigating the processes

5. Improve the quality of the processes

Across the world top private and public organization are utilizing TQM. An initial step for implementing TQM is assessment of the actual position of the organization. There are certain preconditions for implementation of TQM, like considering the history, the present requirements, the quality of life of working employees and the events triggering for implementation of TQM. Thus the implementation necessitate the above mentioned conditions and if they are not met then the implementation should be delayed to such a time till the preconditions are met for the implementation to be successful.

For organizations that have a record of responding effectively to environment, and of successfully being able to change its method of operation when required, it is expected that TQM would be implemented easily. On the other hand for organizations that have the history of being reactive and not known to have successfully improved its modus operandi then we can expect skepticism from the employees and lack of agents that can bring about change. Not to mention that if these conditions remain for a long time then a program for developing the leadership and management required. A good tool for identifying the current position and the areas of improvement is the management audit. Thus the organization must be in a healthy condition before TQM can be implemented. However, TQM is not suitable for organizations that have low employee motivation, poor management, weak administration and unstable funding.

Nonetheless, for initiation of TQM a specific stress level is required. There must be an urge to change in the people Kanter in 1983 described the important factors that can be part of bringing about change in the organization, viz. action vehicle, individuals or "prime movers", strategic decision, a crisis or a crucial event and departing from traditions. Action vehicle are required along with mechanism or structure that can enable change. The plan of TQM implement is a strategic decision and any leader who is ready to take charge of the situation by initiating the idea and to show the benefit to others about how it would take them to their goal, would be the "Prime Mover". All this change can only be brought about if the organization is facing a crisis, which would act as an impetus to bring change. Which in the present situation is TQM, examples of such a crisis could be threat of funding cut, consumer or stakeholders demanding improvement of service quality. However before TQM is implemented there would be activity at the lower level in the organizations that are nonstandard attempts to resolve the issues/crisis which are termed as departure from traditions.

\section{TRANSITION MANAGEMENT}

The steps to manage the transition from an old system to TQM were identified by Pritchard and Beckhard in 1992: identify the task to be performed; create the essential management structure; develop the strategy to build commitment; design the mechanism for communicating the change; finally assign the resource.

To identify the tasks the present condition need to be studied; readiness need to be assessed, e.g force-field analysis; desired state model needs to be created, which is, TQM implementation in the present case; the goals of change need to be announced to the organization; finally the responsibility and resources need to be assigned, which includes to secure training \& consultation from outside, along with assigning an overseer from inside the organization. This assignment is supposed to be done by top management in the organization, along with that the top management is also responsible for designing of the management structure for the transition. According to Hyde, Brand \& Cohen the management should be deeply involved in the process and lead it, instead of a delegating the job to staff for lead the transition. We may also have a steering committee that includes personnel from across the organization. We have already discussed about development of commitment strategy while we talked about employee skepticism vision of the leadership.

For communication of the expected change, we require means apart from the standard communication channels. Meetings aimed at stirring thought process and talk sessions which are attended by all levels can be used to start the implementation. A newsletter would be one of the most effective channel of communication that would announce the latest development and achievements in the process. It is important to effectively manage the resources involved in the implementation and the consultant may always be necessitated. The consultant should be chosen on the basis of kind of relevant experience they have in adaptation of the process to suit the need of the organization. The consultant would play an important part in the initial training of the system and its design, however it would be the employees that need to pass on the training and be an active part of implementation process. The relationship with the consultant must be collaborative in nature and role definition must clearly defined along with established activity specifications.

To summarize, the precondition and the present condition of the organization must be assessed to ensure that there is an urge to change and to establish appropriateness of the TQM implementation. The structure of the organization and the style of leadership should be harmonious with TQM. If any of the above is not fulfilled, then the implementation must be delayed till the time the above are achieved. 
We must remember that it is a time taking, difficult, and comprehensive process, thus the leaders should be able to sustain the commitment level, maintain transparency and visibility, provide the required support and ensure that people are held accountable for the result. The system design should have maximum involvement of the employees along with the maximum possible input from all the stakeholder viz. funding sources, referring agencies and clients etc.

It should always be kept in mind that TQM is a process driven by purpose and it should be in sync with the organization's vision and goal for the future. We can also use TQM as a powerful technique to unleash potential and creativity of the employee, reduce cost and bureaucracy, and improve services to the community and the clients.

\section{TQM - PROSPECTS IN SERVICE INDUSTRY}

For any organization Customer satisfaction is one of the most crucial factor and for the service industry it is in direct connection to Service Quality. The customer may not just be satisfied completely by a quality product, to him what is also relevant is that which comes with the product. Thus the customer is satisfied by not only the quality of the product but also by the service process' quality, in the service industry. The service process is the complete set of transaction that occur between the customer and the service provider. Thus we have consumption, delivery and the selection of the product. In the service industry, Customer satisfaction is on the basis of the following benchmark. The idiosyncratic comparing of the customer's expectation with the experience they had with the service, along with the service outcome, regular services delivery and effective problem-handling. The organization control, evaluate and monitor the behavior of its employees to match the customer's expectation for service. E.g. success or failure of a restaurant might be resultant of the way the waiters treat the customers. Thus we may easily conclude that for the existence of the service industry maintaining of service quality is a must and the in order to achieve service quality application of TQM principals is the only means.

\section{REFERENCES}

[1] Heady and Smith, 1995; Lau and Anderson, 1998

[2] Milakovich, 1995 : Improving service quality: Achieving high performance in the public and private sectors

[3] Rudie and Wansley, 1985; Thomson et al., 1985; Quinn and Humble, 1993; Anderson et al., 1994; Donaldson, 1995; Rust et al., 1995

[4] Dotchin and Oakland, 1994; Kettinger and Lee, 1995 a, b; McDaniel and Louargand, 1994

[5] Garvin, 1988

[6] Galloway, 1996; Kuei, 1999

[7] Berry, 1980; Lovelock, 1983; Parasurman et al., 1985; Zeithaml et al., 1985; Bitner, 1992; Dotchin and Oakland, 1994 a, b, C; Ghobadian Ct al. 1994

[8] Berry et al., 1990

[9] Zeithami et al., 1990

[10] Babakus and Boiler, 1992; LeBlanc and Nguyen, 1997

[11] Sasser et al., 1978 a; Lehtinen and Lehtinen, 1982; Gronroos, 1982, 1984; Lewis and Booms, 1983; Parasuraman et al., 1985; Zeithami et al., 1985

[12] Carman, 1990; Babakus and Boiler, 1992; Cronin and Taylor, 1992; Teas, 1993

[13] Cronin and Taylor, 1992

[14] Galloway and Wearn, 1998

[15] Anderson and Sullivan, 1993

[16] Agarwal, S.,K, and Vrat, p. 1996, quality management self assessment approach for quality improvement.

[17] Kettinger and Lee, 1995

[18] Ahire, S., L., 1996, TQM age versus quality : An empirical investigation. Production and Inventory management journal.

[19] Akella, D., 2003, culture controls within professional firms. Journal of Advances in management research.

[20] Raj Kumar, 2005, Implementation of TQM in industries.

[21] Anantharaman, N., Muralidharan, C., Manickam, S and Krishnan M., 2003, Analysing human factor perceptions of TQM dimensioning using multivariate procedure - A case study.

[22] Anderson, E., A., and Adams, D., A., 1997, Evaluating the success of TQM implementation: Lesson from employees.

[23] Arora, K., C., 2002," Total quality management", kataria and sons, Delhi.

[24] Arya, A.,P., 2000, "Fostering TQM culture in Tata Engineering Jamshedpur. 